\title{
Comparison of dielectric barrier discharge and radio-frequency plasma processing of carbon fibers
}

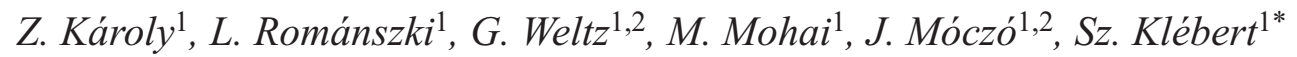 \\ ${ }^{1}$ Institute of Materials and Environmental Chemistry, Research Centre for Natural Sciences, H-1117 Magyar tudósok \\ körútja 2., Budapest, Hungary \\ ${ }^{2}$ Laboratory of Plastics and Rubber Technology, Department of Physical Chemistry and Materials Science, Budapest \\ University of Technology and Economics, H-1521 Budapest, Hungary
}

Received 19 April 2021; accepted in revised form 18 June 2021

\begin{abstract}
Carbon fibers (CFs) are commonly applied reinforcement material in various composites to improve their mechanical, thermal, or electrical properties. The physical and chemical state of the interface, the chemical bonds, and adhesion between the fiber and matrix have a great influence on certain properties of the composite, including the mechanical ones. The originally low adhesion between the CFs and the matrix material can be improved by employing non-equilibrium plasma for surface treatment of the fiber. In the present study, we compared the effect of an atmospheric dielectric barrier discharge (DBD) and a low-pressure radio frequency (RF) plasma processing on poly(acrylonitrile) based and sized CFs in terms of surface chemistry, morphology, and adhesive properties of the treated fibers. It was found that atmospheric DBD plasma treatment induced greater changes in the surface properties of the CFs as compared to RF plasma. The DBD treated CF surface became more oxidized, increasing the $\mathrm{O} / \mathrm{C}$ ratio by $30 \%$, while reaching a twofold increase in the roughness. Surface adhesion improved after both plasma treatments, but it was significantly higher after the atmospheric DBD process.
\end{abstract}

Keywords: polymer composites, cold plasma, sized carbon fiber, adhesion, surface roughness

\section{Introduction}

Carbon fiber $(\mathrm{CF})$ is one of the most widespread reinforcing materials in various composites, including polymers, metals, ceramics, or carbons, owing to its outstanding combination of physical, mechanical, thermal, and electrical properties $[1,2]$. The extra high specific strength $\left(>2000 \mathrm{kNm} \cdot \mathrm{kg}^{-1}\right)$ and modulus $\left(>170 \mathrm{MNm} \cdot \mathrm{kg}^{-1}\right)$ of carbon fibers allow substantial improvement in the mechanical properties of the composites as compared to homogenous materials [3-5]. The full potential of the reinforcing effect of CF in the composite can be harnessed only if sufficiently high adhesion is attained between the fiber and the matrix [5]. In this respect, the polar groups situated at the surface of the fibers play a crucial role in the adhesion of polymer composites as only these moieties are capable of creating chemical bonds. Adhesion can also be improved by increasing the surface area of the contacting phases; however, its contribution to the overall adhesion is debated for polymer composites [6]. CFs, however, inherently lack polar groups at the surface [7-12]. As a consequence, they exhibit poor wettability and low surface free energy, as well as the adhesion between the polymer composite constituents, is weak and so do the mechanical properties of the composites. To achieve better interfacial adhesion between the CF and the polymer matrix, various coating materials, known as sizing agents, are frequently applied onto the CF surface [12-14]. However, adequate binding of the sizing also necessitates available polar groups on the CF. As a consequence, the key step of making

$\overline{{ }^{*} \text { Corresponding author, e-mail: klebert.szilvia@ttk.hu }}$ (C) BME-PT 
a reliably strong $\mathrm{CF} /$ polymer composite is to create polar groups at the surface of CF. Numerous techniques have been developed over the last decades for the surface treatment of CF, including wet [15-17] and dry $[18,19]$ chemical oxidation, anodic oxidation [20], and $\gamma$-ray radiation treatment $[21,22]$. In oxidative treatments, acidic functional groups $(-\mathrm{O}-\mathrm{C}-$, $-\mathrm{C}=\mathrm{O},-\mathrm{O}-\mathrm{C}=\mathrm{O})$ are being formed at the surface layer of the fibers that improve the hydrophilic character and chemical reactivity [23-25]. The above methods, however, are typically time-consuming, burden the environment, and may reduce the strength of the fibers [26]. In contrast, plasma modification representing the most recent trend offers a fast, environmentally friendly, and low-cost technique [27]. The treatment affects only the outermost surface in a thickness of around $10 \mathrm{~nm}$ [28], while the bulk properties, in contrast to earlier mentioned techniques, remain unaltered. The effect of various plasma treatments operating either in atmospheric [29] or lowpressure conditions [30] has been investigated. While almost all plasma treatments efficiently increase the surface energy of CFs, it is still difficult to compare their overall performance since treatments usually show a great difference in the applied operating conditions such as duration of the treatment (from $0.5 \mathrm{~s}$ to several minutes), plasma power, employed gases ( $\mathrm{He}, \mathrm{Ar}, \mathrm{N}_{2}, \mathrm{O}_{2}$, air or their mixtures) and the applied test methods, as well.

In the present paper, we compare the effect of an atmospheric DBD and a low-pressure RF plasma method on poly(acrylonitrile) (PAN) based carbon fibers in terms of the surface chemistry, morphology, and adhesive properties of the treated fibers. Contrary to most earlier papers, we studied carbon fibers covered with sizing as most commercial CFs are available in this form and more relevant in terms of industrial processing. We did not intend to remove this layer but to explore if adhesion can be further increased by modification of the surface chemistry and/or morphology.

\section{Materials and methods}

PAN-based CFs (Panex 35) with sizing supplied by Zoltek Zrt. (a subsidiary of Toray Group, Nyergesújfalú, Hungary) were used in the experiments. The diameter of the fibers was $7 \mu \mathrm{m}$. The fibers were subjected to plasma treatment without any previous cleaning or de-sizing.
The atmospheric plasma system used for surface activation was a commercial diffuse coplanar surface dielectric barrier discharge (DCSDBD) unit (Roplass sro., Brno, Czech Republic). The discharge was operated in air at $300 \mathrm{~W}$, which provided a quasi-homogeneous diffuse plasma surface. The discharge frequency was $10-20 \mathrm{kHz}$ with a voltage of $20 \mathrm{kV}$. The design of the plasma set-up is detailed in other papers [31,32]. The treatment time was set to 10 and $60 \mathrm{~s}$. Prior to treatment, individual CFs were removed from the bundle and fixed to cardboard, then placed on the flat dielectric panel.

Low-pressure RF plasma treatments were performed in a UHV system (base pressure $<1 \cdot 10^{4} \mathrm{~Pa}$ ), in airflow $\left(<5 \mathrm{~cm}^{3} / \mathrm{min}\right.$ STP) regulated by a bleeding valve to set the pressure to $5-8 \cdot 10^{-1} \mathrm{~Pa}$. The RF power $(13.56 \mathrm{MHz}, 100 \mathrm{~W})$ was applied through a matching circuit to a coil set outside of a glass dome fixed to the chamber. A negative DC bias of $150 \mathrm{~V}$ was applied through the steel sample holder. The applied treatment times were 180 and $300 \mathrm{~s}$.

\section{Characterization of the materials}

The surface chemistry of the treated and untreated fibers was analyzed by X-ray photoelectron spectroscopy (XPS). Spectra were recorded on a Kratos XSAM 800 spectrometer ((Kratos Analytical Ltd., Manchester, UK)) operated at fixed analyzer transmission mode, using $\mathrm{Mg} \mathrm{K} \alpha_{1,2}(1253.6 \mathrm{eV})$ excitation. The pressure of the analysis chamber was lower than $1 \cdot 10^{-7} \mathrm{~Pa}$. Survey spectra were recorded in the $150-1300 \mathrm{eV}$ kinetic energy range with $0.5 \mathrm{eV}$ steps. Photoelectron lines of the main constituent elements, i.e., the $\mathrm{C} 1 \mathrm{~s}, \mathrm{~N} 1 \mathrm{~s}, \mathrm{O} 1 \mathrm{~s}$, and $\mathrm{Si} 2 \mathrm{p}$ were recorded by $0.1 \mathrm{eV}$ steps. Spectra were referenced to the energy of the $\mathrm{C} 1 \mathrm{~s}$ line of the $\mathrm{sp}^{2}$ type graphitic carbon, set at $284.3 \pm 0.1 \mathrm{eV}$ B.E. (binding energy). Quantitative analysis, based on area intensity after Shirley type background removal, calculated by the infinitely thick homogeneous model, was performed by the XPS MultiQuant 7.8 program [33] using the experimentally determined photo-ionization cross-section data of Evans et al. [34] and asymmetry parameters of Reilman et al. [35].

The morphology of fibers was characterized by scanning electron microscopy (SEM, Zeiss DSM982 GEMINI with a heated field emission tungsten cathode) (Oberkochen, Germany) and atomic force microscopy (AFM). AFM scans of individual fibers 
were performed in ambient condition, at room temperature, in contact mode using a Dimension 3100 AFM equipped with a NanoScope IIIa controller (Digital Instruments/Veeco, Santa Barbara, California, USA). The following parameters were applied: typical scan sizes $2 \times 2$ and $4 \times 4 \mu \mathrm{m}^{2}$, typical scan rate $1 \mathrm{~Hz}, 512 \times 512$ pixels per image. Nanosensors TM PPP-NCHR-20 type silicon cantilevers (thickness: $40 \pm 1 \mu \mathrm{m}$; length: $125 \pm 10 \mu \mathrm{m}$; width: $30 \pm 7.5 \mu \mathrm{m}$; typical resonance frequency $\sim 293 \mathrm{kHz}$; force constant: $10-130 \mathrm{~N} / \mathrm{m}$; aluminium-coated top; tip height: $10-15 \mu \mathrm{m})$ were used in Tapping Mode. Scanned areas were around the apex of the fiber samples lying on a Si 100 wafer. The fast scan direction was perpendicular to the main fiber axis. To correct for tilt, a $1^{\text {st }}$ order plane fit was applied to the raw image data. For roughness characterization, two different approaches have been used:

1. The two most widespread $[36,37]$ areal $\left(S_{\mathrm{a}}, S_{\mathrm{q}}\right)$ roughness parameters have been determined for each image.

2. The corresponding linear roughness parameters, $R_{\mathrm{a}}$ and $R_{\mathrm{q}}$, have been determined along a number of selected longitudinal sections of each image for 2 and $4 \mu \mathrm{m}$ lengths.

For the areal parameters, the number of images was: untreated and RF-treated fibers, both $2 \times 2 \mu \mathrm{m}^{2}$, and $4 \times 4 \mu \mathrm{m}^{2}-6$ each; DBD-treated fibers, both $2 \times 2 \mu \mathrm{m}^{2}$, and $4 \times 4 \mu \mathrm{m}^{2}-7$ each; with $512 \times 512$ data points per each image. For the linear parameters, the number of section lines was: untreated fibers, $2 \mu \mathrm{m}-59$; untreated fibers, $4 \mu \mathrm{m}-74$; RF-treated fibers, $2 \mu \mathrm{m}-18$; RF-treated fibers, $4 \mu \mathrm{m}-35$; DBD-treated fibers, $2 \mu \mathrm{m}-35$; DBD-treated fibers, $4 \mu \mathrm{m}-44$; with approx. 512 data points per image.

The tensile properties of neat and plasma-treated elemental fibers were determined using an Instron 5566 mechanical testing apparatus ((Instron Co., Canton, $\mathrm{OH}, \mathrm{USA})$.) equipped with a $10 \mathrm{~N}$ measurement

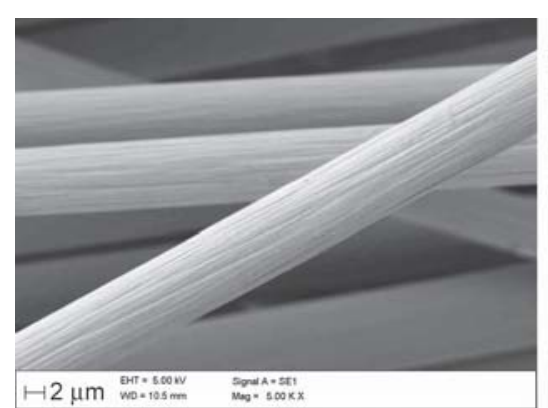

a)

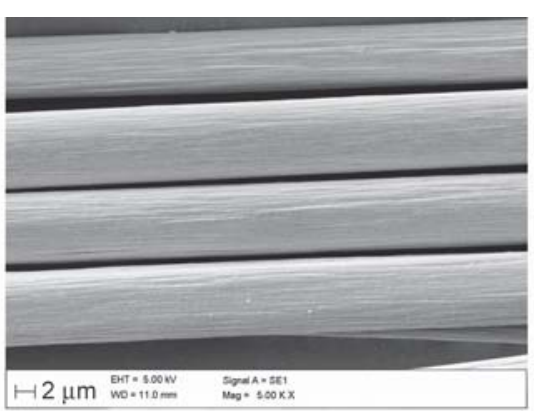

b) head. The distance of the clamps was $22 \mathrm{~mm}$, and the cross-head speed was $0.5 \mathrm{~mm} / \mathrm{min} .30$ parallel measurements were carried out.

The interfacial shear stress (IFSS) was determined by fragmentation. During the measurements, the specimen, consisting of a single fiber embedded in the epoxy, was continuously stretched with $1.25 \% \mathrm{~min}^{-1}$ cross-head speed with a Zwick/Roell tensile machine (Ulm, Germany) until the fiber in the matrix broke into small pieces. The epoxy matrix used consisted of a glycerol-based epoxy resin (MR 3012) and a modified amine hardener (MH 3122), both purchased from Ipox Chemicals Ltd., Budapest, Hungary. Curing was carried out in two steps, first at room temperature for $10 \mathrm{~min}$ followed by the second step at $80^{\circ} \mathrm{C}$ for $24 \mathrm{~h}$ under vacuum. Five parallel measurements were carried out, and the number of fragments, as well as their length, was measured under a light microscope (Keyence - VHX 5000, equipped with a VH-Z100UT objective, Osaka, Japan) after reaching the maximum number of fragments. IFSS was calculated by the Kelly-Tyson equation shown in Equation (1) [38]:

$\tau=\frac{d \cdot \sigma_{\mathrm{f}}}{2 \cdot l_{\mathrm{c}}}$

where $d$-diameter of the fiber, $\sigma_{\mathrm{f}}-$ tensile strength, $l_{\mathrm{c}}-$ critical fiber length.

\section{Results and discussion}

\subsection{Morphological study}

SEM images of untreated and plasma-treated fibers are shown in Figure 1, respectively. Striations discernible at the surface of the untreated fibers in the longitudinal direction are originating from the fiber manufacturing process [39-42]. The striations remained visible after plasma treatment regardless of the plasma type. On DBD plasma-treated CFs, small, loosely bonded particles or globules are also

Figure 1. SEM micrographs of untreated (a), RF treated (b), and DBD treated (c) carbon fibers, respectively. 
perceptible, which could be attributed to the formation of low molecular weight oxidized material (LMWOM) [43] originating from the sizing agent. LMWOM is developed at the surface as a result of a degradation of the organic substance taking place in parallel with surface functionalization, especially when oxygen is present in the system. Such particles could also be detected sporadically in the case of RF treatment; however, compared to DBD treatment, their frequency was negligible, possibly due to the milder condition of the RF plasma.

A more detailed morphological investigation was performed by AFM, leading to both qualitative and quantitative results.

\section{Qualitative observations}

Under AFM, the striations observed by SEM are visible in detail. Additionally, a patchy, vermiculate fine structure of the untreated surface is revealed, consisting of pits and ridges, with characteristic lateral dimensions of a few tens of [nm], and a characteristic depth of 4-5 nm, aligned along the axis of the secondary fiber beams formed by the striations (Figure 2). The patchy pattern presumably is formed owing to the imperfect wetting of the CF by the sizing agent, while the bottom of the pits represents the surface of the CF. After both plasma treatments, the striations and the secondary fiber beams are preserved, but this fine structure is partially lost due to the etching effect of the plasma, and humps of a few tens of nm typical size appear (Figure 3). In the case of DBD-treated fibers, a large number of humps are visible along the edges of the secondary fiber beams.

\section{Quantitative comparison}

Figure $4 \mathrm{a}$ shows a typical $4 \times 4 \mu \mathrm{m}^{2}$ image consisting of $512 \times 512$ data points, only first-order plane-fitted (corrected for tilt), used to determine areal parameters $S_{\mathrm{a}}$ and $S_{\mathrm{q}}$. As the primary curvature of the image is perpendicular to the fiber axis, the obtained crosssectional $R_{\mathrm{a}}$ and $R_{\mathrm{q}}$ linear roughness parameters are practically identical to the areal roughness parameters of the whole image [44], and therefore have not been used in the comparison (Figure $4 b$ ). Instead, the linear roughness parameters of multiple longitudinal sections (parallel to the secondary beam axes) have been determined and compared across the three different type samples (Figure 4c). In Figure 5, a boxplot statistical representation is shown of the several individual $S_{\mathrm{a}}$ and $S_{\mathrm{q}}$ areal roughness parameters obtained for separate images of the same size and sample type. The roughness of the RF-treated CFs
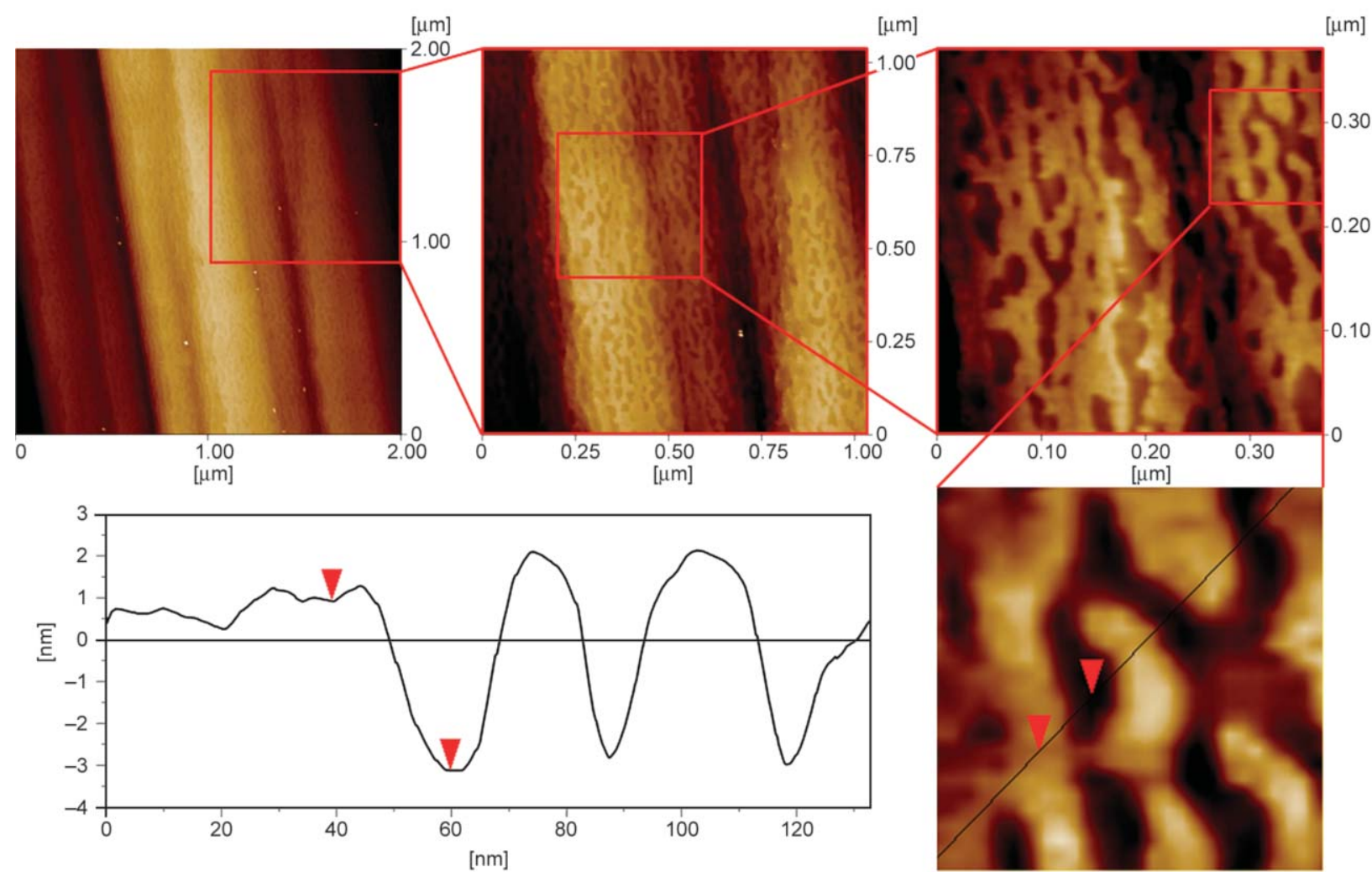

Figure 2. AFM images of an untreated carbon fiber surface in consecutive magnifications and a cross-section showing 4-5 $\mathrm{nm}$ as typical feature height (profile plot not to scale). 

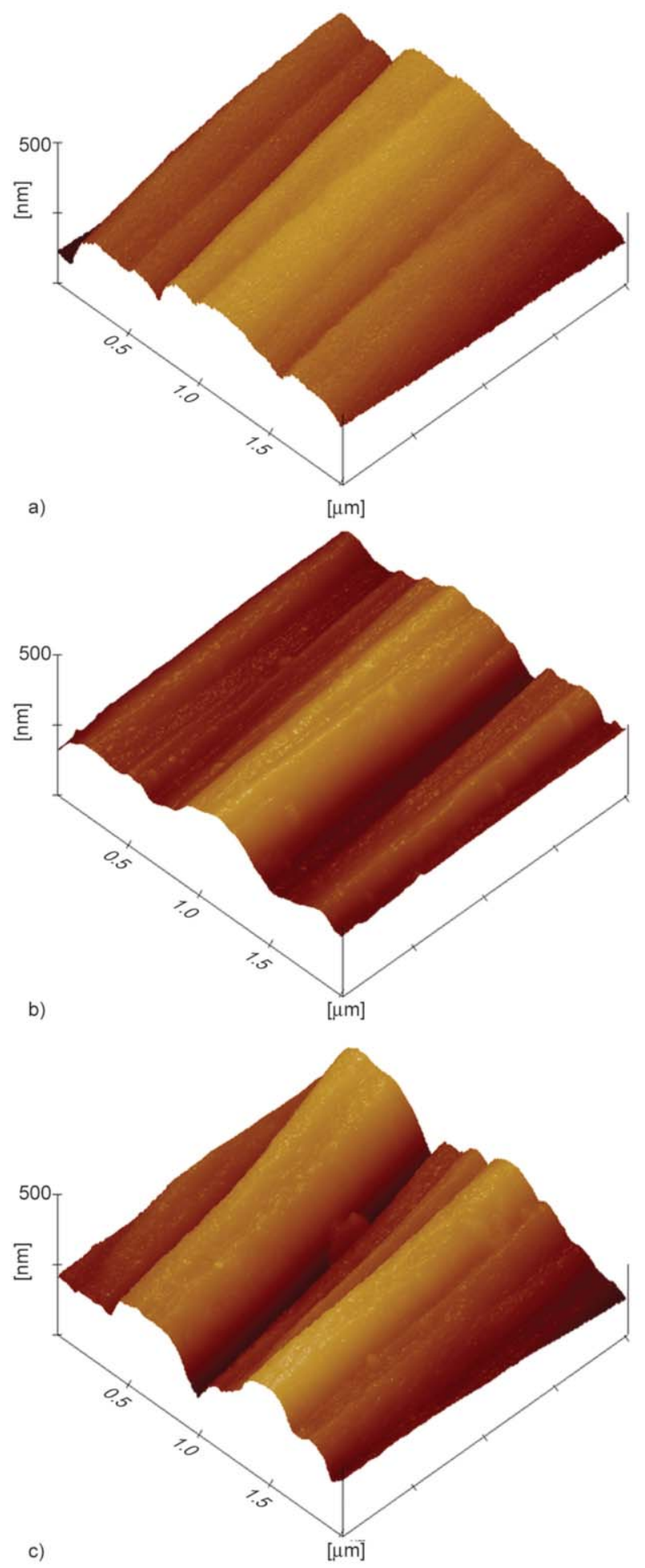

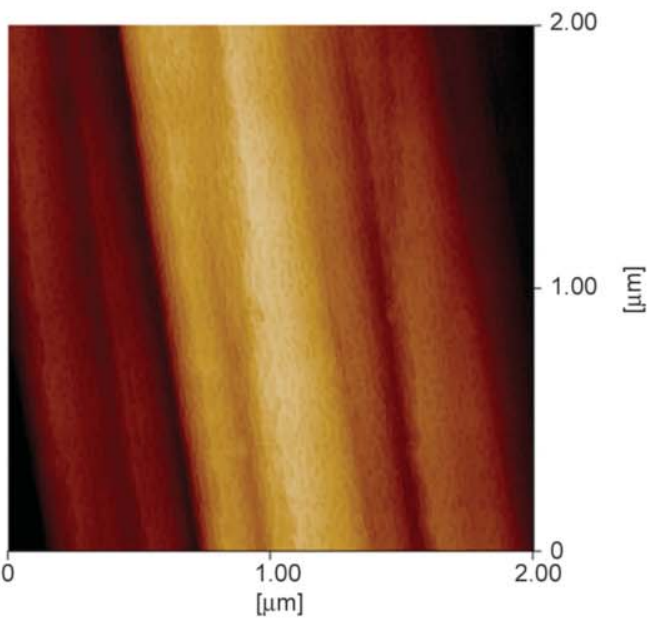

b)

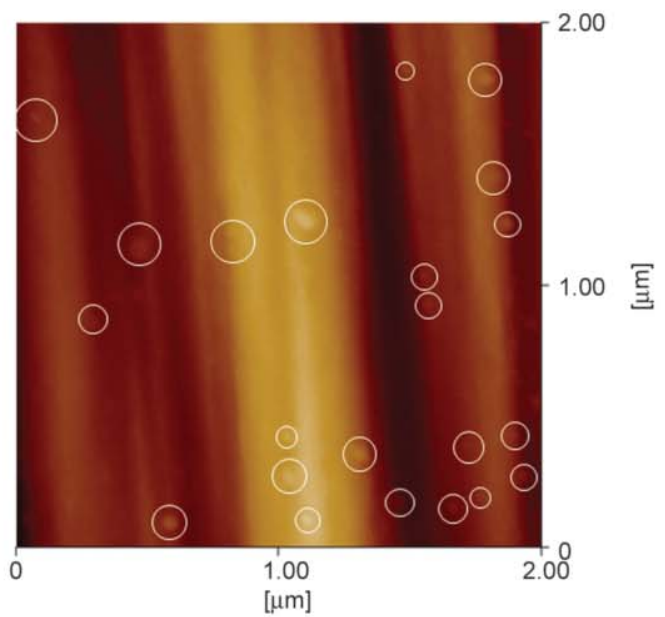

d)

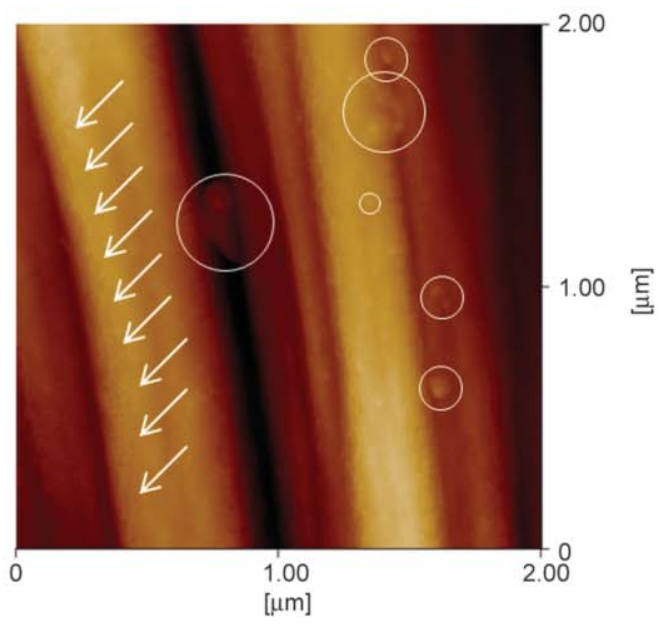

Figure 3. $2 \times 2 \mu \mathrm{m}^{2}$ representative surface topography images of untreated (a, b), RF-treated (c, d), and DBD-treated (e, f) fibers, in 3D (a, c, e) and top view (b, d, f). Circles indicate debris-like humps, while arrows indicate a series of humps aligned at the edge of a secondary fiber beam.

is apparently higher than that of untreated ones for both scan sizes and both roughness parameters; however, based on the criterion of partially or mutually overlapping medians and adjacent boxes, the statistical significance of this result counts as either low (for the $2 \times 2 \mu \mathrm{m}^{2}$ areas), or even nil (for the $4 \times 4 \mu \mathrm{m}^{2}$ areas). Contrarily, the statistical significance of the difference between the areal roughness of the DBDtreated fibers and both the untreated and the RFtreated fibers is definite. Areal roughness parameters of the same sample types are typically two-three times higher for larger scan sizes, which is a direct 

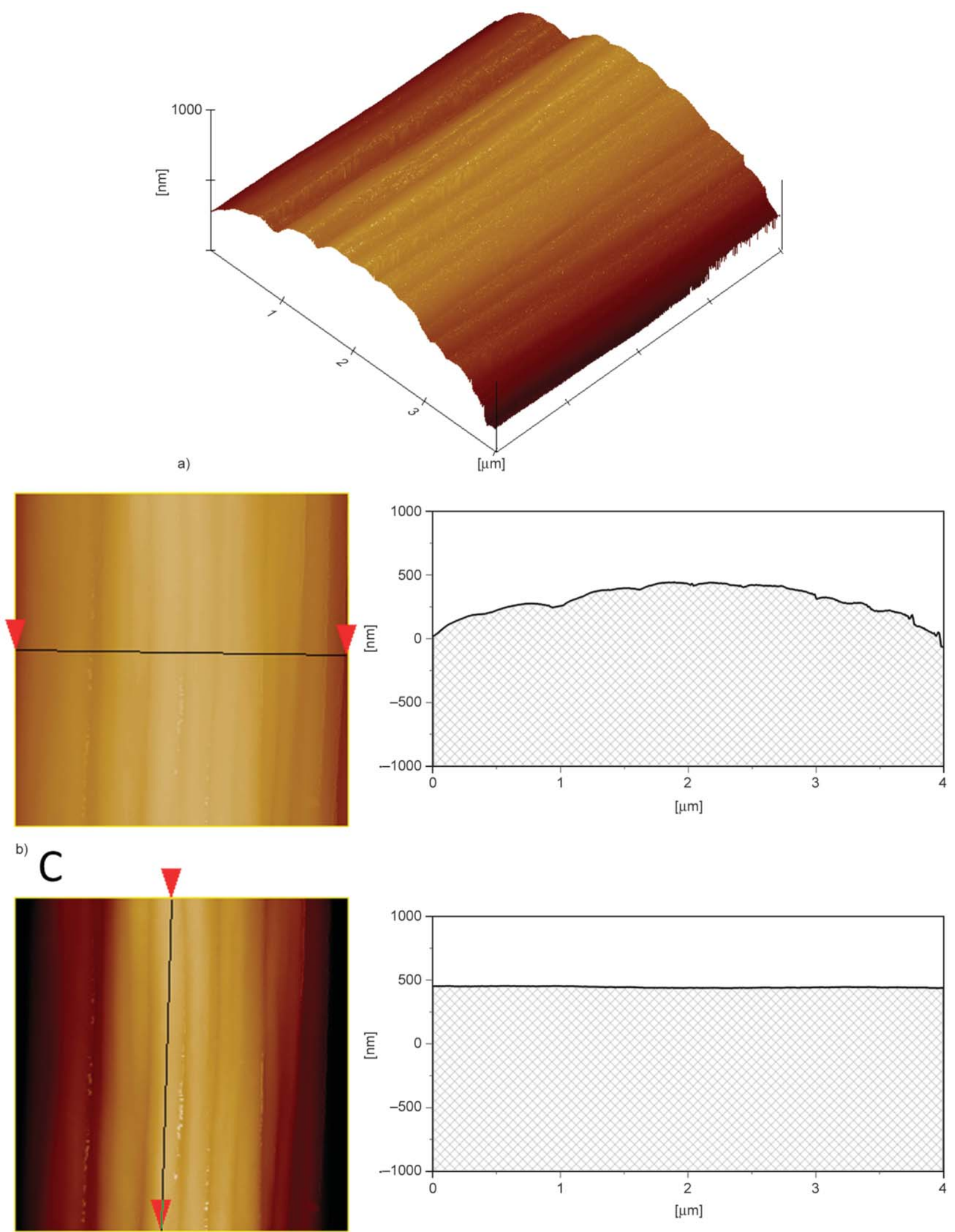

c)

Figure 4. Roughness determination, illustrated with the example of an untreated carbon fiber AFM image. (a) Areal roughness parameters (in the case shown, $S_{\mathrm{q}}=119.24 \mathrm{~nm}$ and $S_{\mathrm{a}}=99.433 \mathrm{~nm}$ ) were determined for the whole image, consisting of $512 \times 512$ data points. Cross-sections like (b) were not used for linear roughness parameter determination (in the case shown, $R_{\mathrm{q}}=118.52 \mathrm{~nm}$ and $R_{\mathrm{a}}=99.419 \mathrm{~nm}$ ). Longitudinal sections such as (c), multiple per image, approx. 512 data points per line, have been used for linear roughness parameter determination (in the case shown, $\left.R_{\mathrm{q}}=6.499 \mathrm{~nm} ; R_{\mathrm{a}}=3.152 \mathrm{~nm}\right)$. Note that the corresponding profile plots are to scale. 

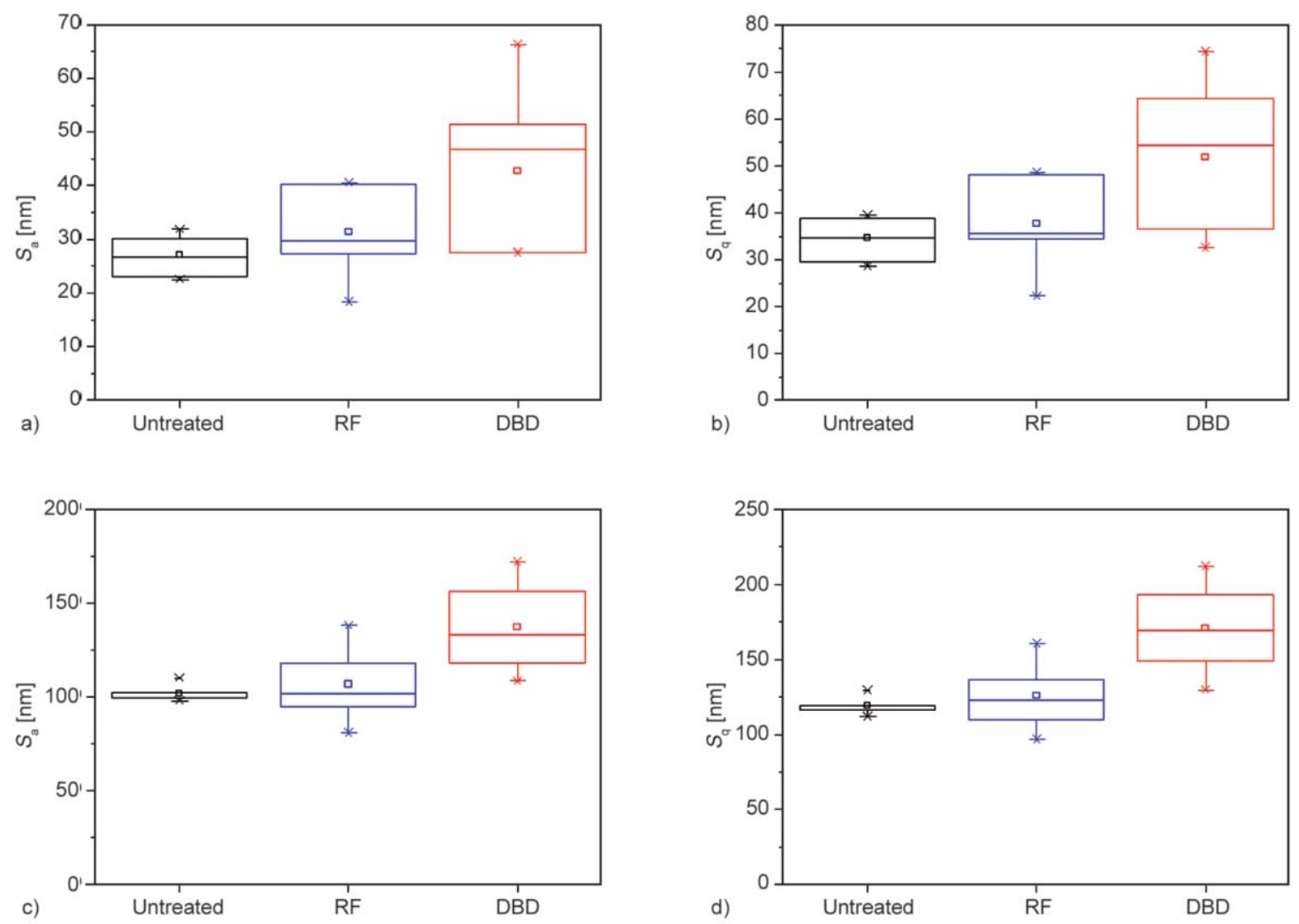

Figure 5. Boxplot statistics representation of $S_{\mathrm{a}}(\mathrm{a}, \mathrm{c})$ and $S_{\mathrm{q}}(\mathrm{b}, \mathrm{d})$ roughness parameters of untreated, RF-treated, and DBDtreated carbon fire samples, for $2 \times 2(a, b)$, respectively $4 \times 4 \mu \mathrm{m}^{2}(\mathrm{c}, \mathrm{d})$ scan sizes. Conventional boxplot notations have been used: bottom, mid and top box lines represent the 25,50 , and 75 percentiles respectively (interquartile range, IQR); $\times$ stand for 1 and 99 percentiles; whiskers extend from minimum to maximum values lying within $1.5 \times \mathrm{IQR}$ distance; means are labeled with $\square$.

consequence of the larger main curvature arc considered in the calculation. The linear roughness parameters calculated along the longitudinal sections are free of this main curvature effect; consequently, they increase slightly with increasing scan size (Figure 6). The general findings that the median and the mean of the roughness parameter distribution is slightly higher for the RF-treated samples than for the untreated samples is repeated, however, again without much statistical relevance. Contrarily, the linear roughness parameters of the DBD-treated samples are clearly and significantly higher than both that of the untreated and the RF-treated samples, and, as expected, this difference is even more pronounced than for the case of the corresponding areal parameters. In conclusion, and in line with the qualitative observations and also the SEM results, the RF plasma treatment only slightly increased the roughness of the carbon fiber surfaces, while the DBD plasma treatment had a much stronger effect.

\subsection{XPS characterization}

The X-ray photoelectron spectra of the untreated and plasma-treated samples are presented in Figure 7. Although the differences due to treatments are clearly visible, the line shapes are similar. The overall surface compositions are shown in Table 1. The DBD plasma treatments significantly increase the oxygen and slightly change the nitrogen concentration. The RF plasma treatments practically do not alter the oxygen content but significantly increase the nitrogen concentration.

The CFs are not stoichiometric compounds; while the bulk is expected to be pure carbon, the actual surface composition may vary with the antecedents of the sample (e.g., storage temperature, oxygen pressure, UV exposure, etc.) as well as the composition of the sizing. The chemical structure (qualitative and quantitative) cannot be exactly derived from the spectra. However, the complex spectral lines can be decomposed to different chemical states, based on 

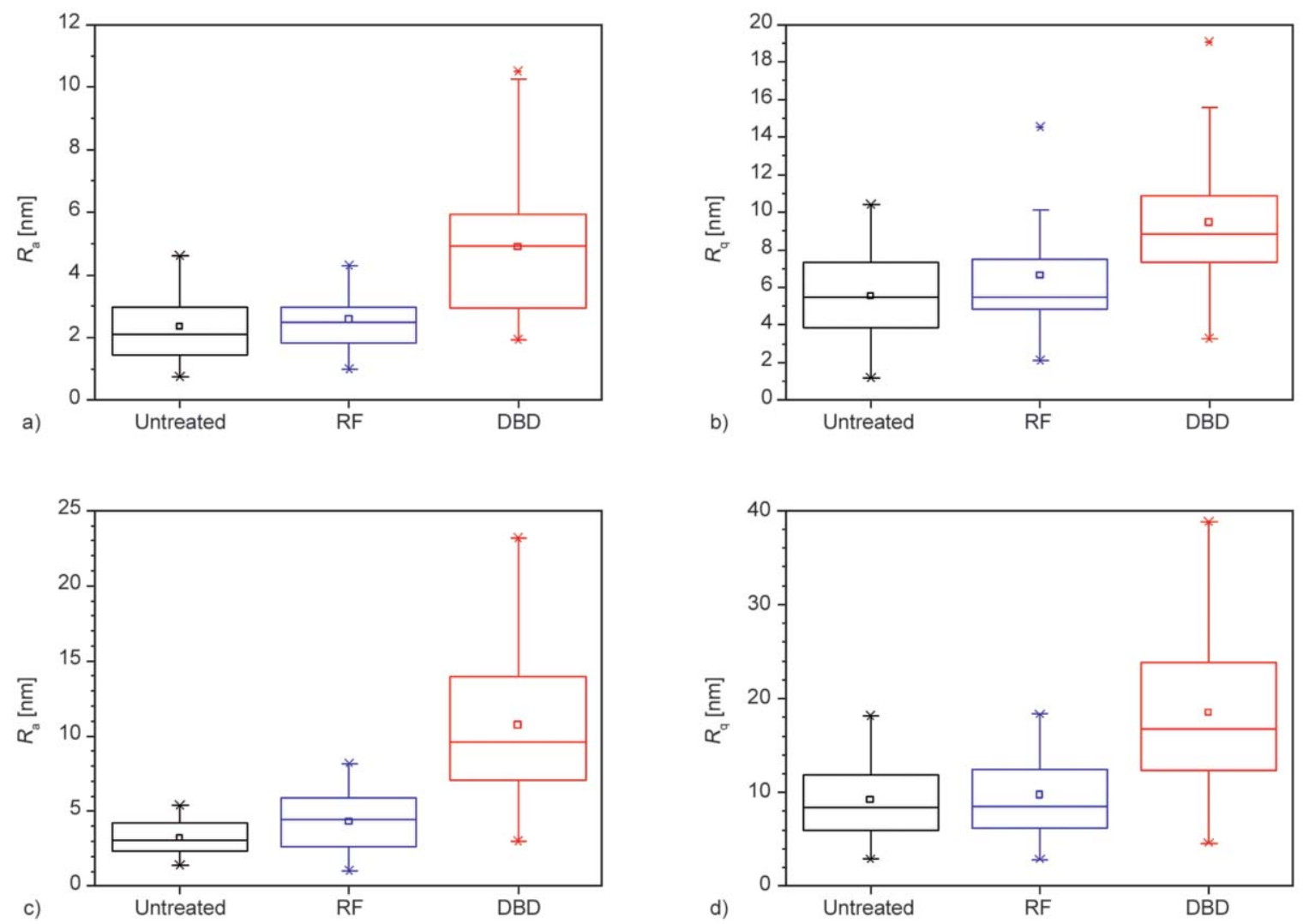

Figure 6. Boxplot statistics representation of $R_{\mathrm{a}}(\mathrm{a}, \mathrm{c})$ and $R_{\mathrm{q}}(\mathrm{b}, \mathrm{d})$ roughness parameters of untreated, RF-treated, and DBDtreated carbon fiber samples, for $2(a, b)$, respectively $4 \mu \mathrm{m}(\mathrm{c}, \mathrm{d})$ scan sizes. Conventional boxplot notations have been used (see Figure 5).

Table 1. Overall surface composition [atomic \%] of the untreated and plasma-treated samples. The relative error of the XPS measurements is $\pm 5 \%$.

\begin{tabular}{|l|r|r|r|c|c|}
\hline Treatment & $\begin{array}{c}\text { Time } \\
{[\mathbf{s}]}\end{array}$ & $\mathbf{O}$ & $\mathbf{N}$ & $\mathbf{C}$ & $\mathbf{O} / \mathbf{C}$ \\
\hline Untreated & 0 & 12.3 & 3.3 & 84.4 & 0.15 \\
\hline DBD & 10 & 16.3 & 4.8 & 78.9 & 0.20 \\
\hline DBD & 60 & 17.6 & 2.9 & 77.8 & 0.23 \\
\hline RF & 180 & 12.1 & 3.9 & 84.0 & 0.14 \\
\hline RF & 300 & 13.0 & 5.6 & 80.7 & 0.16 \\
\hline
\end{tabular}

literature data of several polymers [46], as illustrated in Figure 8, although some minor components may not be distinguished/separated. All samples can be decomposed by the same scheme but the ratios of the components are different. The main bonding states can be assigned to the components as shown in Figure 9.

The quantitative composition of the chemical states, together with the binding energy of the components,
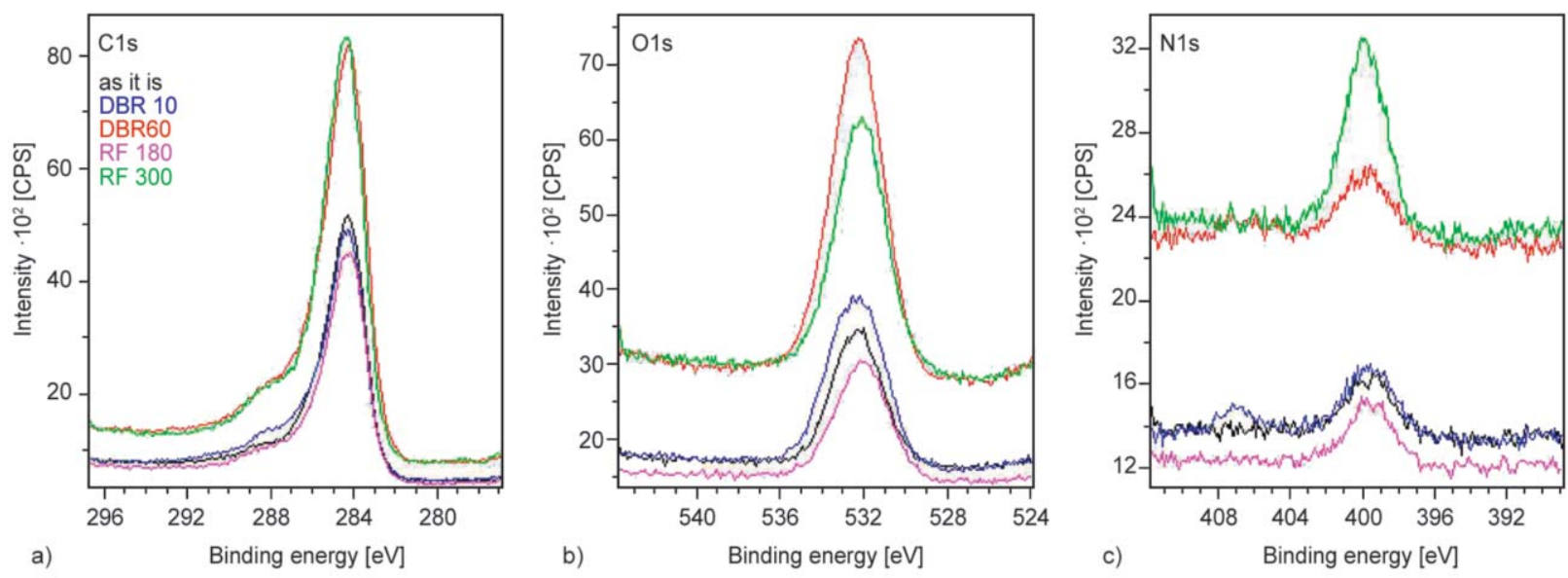

Figure 7. Comparison of the X-ray photoelectron spectra of the untreated and plasma-treated sampless: the C1s (a), O1s (b) and N1s (c) lines. 

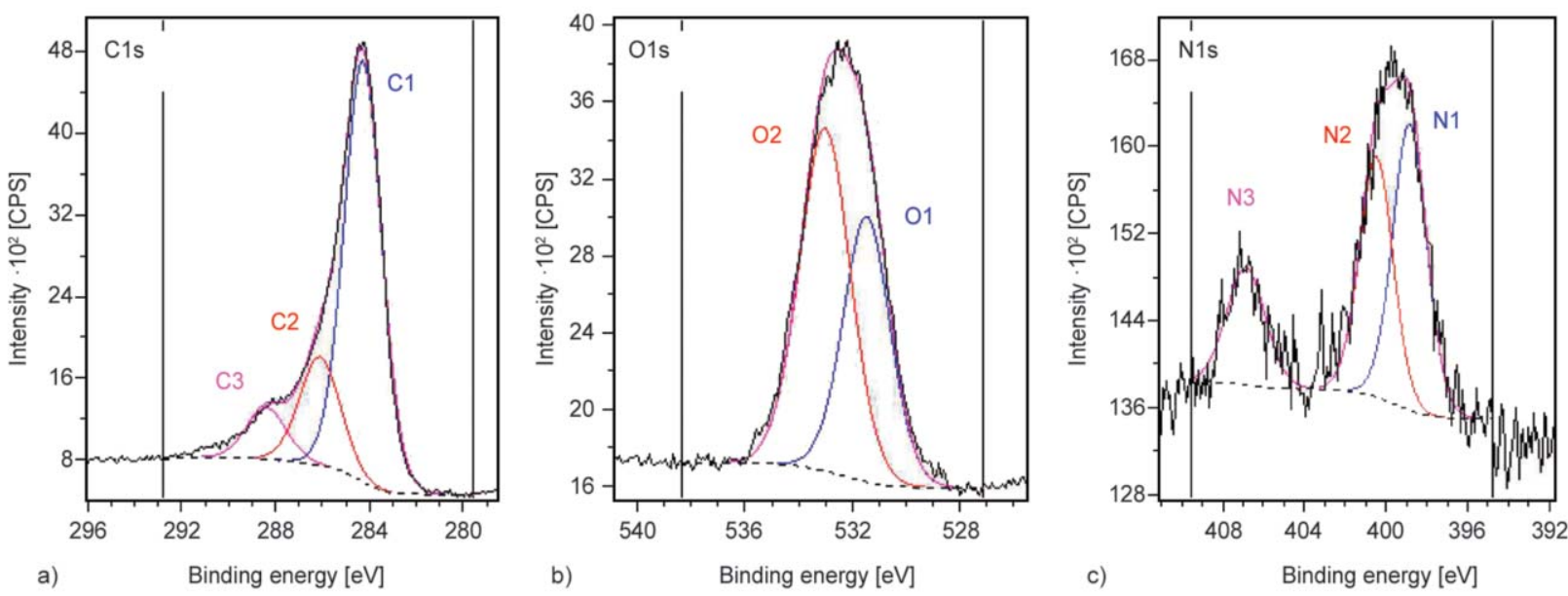

Figure 8. Decomposition of the photoelectron spectra of a selected typical sample (10 s DBD); the C1s (a), O1s (b) and N1s (c) lines.

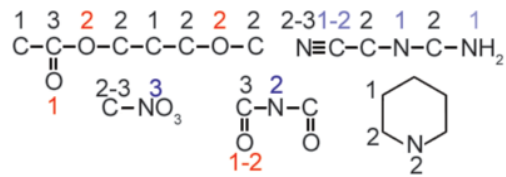

Figure 9. Plausible assignment of components to chemical states based on literature data [45].

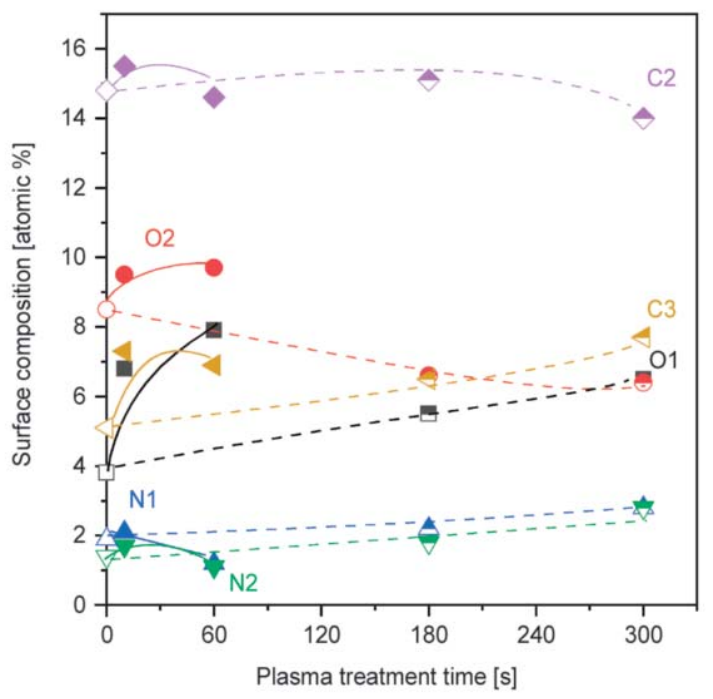

Figure 10. Surface composition of chemical states of the untreated and plasma treated samples. Solid lines: DBD plasma, dashed lines: RF plasma. C1 carbon not shown; open symbols stand for untreated CF samples. are shown in Table 2 and illustrated in Figure 10. These results indicate that the level of both oxygen types increased after DBD plasma treatment; moreover, the $\mathrm{O} 1$ to $\mathrm{O} 2$ ratio was also increased. The $\mathrm{RF}$ plasma increased the $\mathrm{O} 1$ but decreased the $\mathrm{O} 2$ oxygen content, and the $\mathrm{O} 1$ to $\mathrm{O} 2$ ratio is close to one. The nitrogen content slightly increased after the first treatment step for both plasma processes. After longer treatment times, however, it was nearly halved in the DBD, while increased even further in the RF plasma processes. The $\mathrm{N} 1$ to $\mathrm{N} 2$ ratio is not varied significantly. The nitrate type nitrogen $\mathrm{N} 3$ occurs only after DBD plasma treatment, presumably due to its higher ion energy density.

\subsection{Mechanical studies}

Even though one of the main advantages of plasma surface treatment is that it leaves the bulk unaffected, several authors reported on modified mechanical properties of CFs after plasma treatment [46]. The tensile strength of CFs typically decreases due to the formation of micro pits and voids after plasma treatment [47]. The final strength loss can greatly vary depending on the applied power and time [47]. In Table 3 , the tensile strength and strain values are

Table 2. Surface composition [atomic \%] and binding energy [eV] of the components of the untreated and plasma-treated samples. Complex lines are decomposed into chemical states.

\begin{tabular}{|l|c|c|c|c|c|c|c|c|c|c|}
\hline Treatment & $\begin{array}{c}\text { Time } \\
{[\mathbf{s}]}\end{array}$ & $\mathbf{O 1}$ & $\mathbf{O 2}$ & $\mathbf{N 1}$ & $\mathbf{N 2}$ & $\mathbf{N 3}$ & $\mathbf{C 1}$ & $\mathbf{C 2}$ & $\mathbf{C 3}$ & O1/O2 \\
\hline BE $[\mathrm{eV}]$ & & 531.5 & 532.9 & 399.0 & 400.5 & 406.8 & 284.3 & 286.0 & 288.3 & \\
\hline Untreated & 0 & 3.8 & 8.5 & 1.9 & 1.4 & & 64.5 & 14.8 & 5.1 & 0.45 \\
\hline DBD & 10 & 6.8 & 9.5 & 2.1 & 1.7 & 1.0 & 56.1 & 15.5 & 7.3 & 0.72 \\
\hline DBD & 60 & 7.9 & 9.7 & 1.2 & 1.1 & 0.5 & 57.3 & 14.8 & 7.0 & 0.81 \\
\hline RF & 180 & 5.5 & 6.6 & 2.2 & 1.8 & & 62.4 & 15.1 & 6.5 & 0.83 \\
\hline RF & 300 & 6.5 & 6.4 & 2.8 & 2.8 & & 59.4 & 14.1 & 7.8 & 1.02 \\
\hline
\end{tabular}


Table 3. Mechanical properties of untreated and plasmatreated CFs.

\begin{tabular}{|c|c|c|c|}
\hline & Untreated & DBD treated & RF treated \\
\hline Tensile strength [GPa] & $3.5 \pm 1.0$ & $3.2 \pm 0.7$ & $3.6 \pm 0.7$ \\
\hline Tensile strain $\quad[\%]$ & $1.4 \pm 0.4$ & $1.2 \pm 0.2$ & $1.4 \pm 0.2$ \\
\hline
\end{tabular}

shown for the untreated and plasma-treated CFs, respectively. Among the plasma-treated CFs we performed the tests on samples exposed to longer treatment time, i.e., $60 \mathrm{sec}$ of DBD, and $300 \mathrm{sec}$ of RF plasma treatment. While RF plasma-treated CF's strength practically equals that of the untreated one, the DBD treatment decreased the strength by $c a .10 \%$.

\subsection{Adhesion}

The most important reason for CFs' surface treatment is to improve the adhesion between the fiber and the matrix of the composite. The increased number of polar groups on the surface of CFs suggests a good indication of an improved adhesion; however, exact measurements were made by means of fragmentation tests. Figure 11 shows the frequency of the CFs of different lengths for the untreated and the plasma-treated CFs, while the mean and critical values of the CFs are compared in Table 4.

All fragmentation histograms are skewed right and unimodal, which suggests that CFs tend to break into smaller segments. However, the mode of the histogram is considerably smaller for the plasma-treated samples indicating that adhesion between CFs and the epoxy matrix was higher after treatment. In addition, there is also a significant difference between

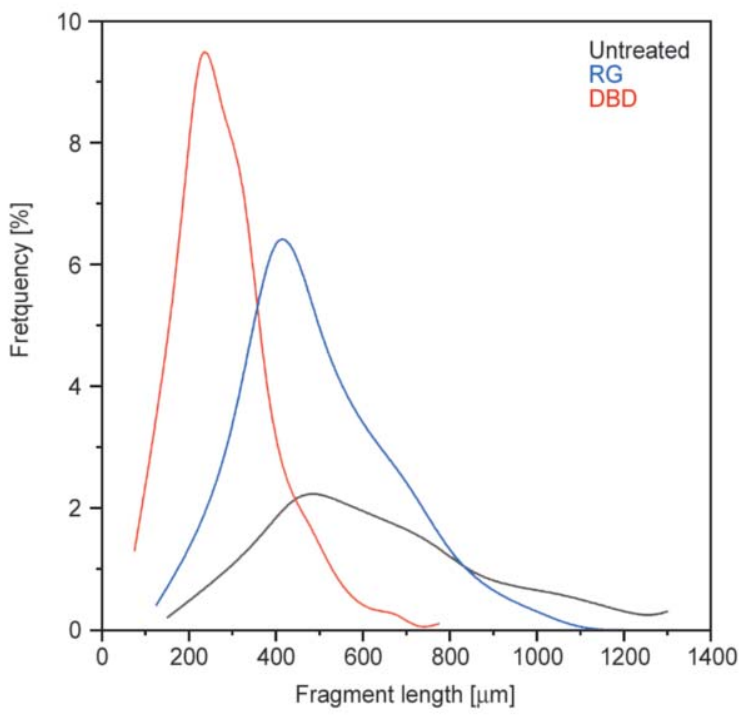

Figure 11. Frequency diagram of the fragmentation tests of CFs for different treatment conditions.
Table 4. Result of the fragmentation tests for the untreated and plasma-treated CFs.

\begin{tabular}{|c|c|c|c|}
\hline & Untreated & DBD & RF \\
\hline Mean length of fragmented CFs $[\mu \mathrm{m}]$ & 593 & 280 & 497 \\
\hline Shear strength & 7.3 & 52.7 & 33.8 \\
\hline
\end{tabular}

the effects of the two types of plasma treatment. DBD treated CFs show a further improved adhesion as compared to RF plasma treatment. Mean values of the length of the fragmented CFs show a similar trend. DBD treated CFs have half the average length than that of the untreated one suggesting a great improvement in the adhesion and as a consequence, in the shear strength too.

\section{Discussion}

Regardless of the applied gases, pressure, and type of plasma, the treatment generally leads to a more polar surface with a considerable decrease in the carbon content of the surface [23]. Consequently, the $\mathrm{O} / \mathrm{C}$ ratio increases. Although some papers report on the formation of new polar groups [48], typically, only the number of oxygen-containing moieties increases. We recorded a significant rise (33 and 53\%) in the $\mathrm{O} / \mathrm{C}$ ratio after 10 and 60 seconds of DBD treatment. This is in accordance with the literature. Even a few seconds of DBD treatment may increase the $\mathrm{O} / \mathrm{C}$ ratio from 0.16 to 0.18 , as reported by Kusano et al. [5]. However, considerably higher, a two or threefold increase in the $\mathrm{O} / \mathrm{C}$ ratio could be achieved at a higher power level or longer treatment time [23, 24]. For instance, Santos studied the effect of the treatment time and reported a twofold and threefold increase after 2 and 10 minutes of DBD plasma treatment, respectively. However, even a $30 \%$ increase in the $\mathrm{O} / \mathrm{C}$ ratio considerably increases the surface energy that improves wettability and enables to achieve better adhesion to the polymer matrix.

Amplitude roughness parameters typically become higher due to the etching effect of the plasma. A twofold increase in the $R_{\mathrm{q}}$ value of the CF surface after 1 or 2 min of treatment by atmospheric air DBD was achieved [23, 24, 48]; however, increasing the treatment time even more, did not considerably increase the roughness. Kostov et al. [43] concluded that increasing power resulted in higher roughness reaching a twofold increase after $70 \mathrm{~s}$ of atmospheric plasma treatment at 200 and $300 \mathrm{~W}$ power comparing with the untreated CF. Interestingly, we also achieved a roughly twofold increase by a mere $10 \mathrm{~s}$ 
DBD treatment, while RF plasma treatment made no considerable changes in the roughness even after $3 \mathrm{~min}$. The subdued etching effect of RF plasma can be attributed to the lower number of ionized species as compared to atmospheric plasma [49]. Intensive etching, however, gives rise to various flows at the surface, such as micro pits and voids that, together with a rougher surface, may ultimately lead to deterioration of the mechanical properties. Accordingly, the tensile strength and strain of treated CFs show a similar picture as roughness. After RF treatment, the original tensile strength of the untreated fibers was preserved; after DBD treatment, it decreased by ca. $10 \%$. However, such a small decrease in the strength does not hinder the application of CFs as a reinforcing phase in, e.g., plastic composites, considering the large difference between the tensile strength values of the different materials. More serious decreases up to $40 \%$ in the tensile strength have been reported by many others after DBD plasma treatment [47]. RF plasma treatment can also induce a slight decrease in the strength but typically only after several minutes ( $>5 \mathrm{~min}$ ) [46].

Plasma treatments principally change the chemical composition and the roughness of the treated surfaces that in turn have an effect on a series of other properties, including wettability, mechanical properties or adhesion, etc. Considering enhanced mechanical properties as an ultimate goal, strong adhesion between the CF and polymer matrix is of utmost importance. The polarity of the CFs' surface, and thus the $\mathrm{O} / \mathrm{C}$ ratio, as well as increased surface roughness,

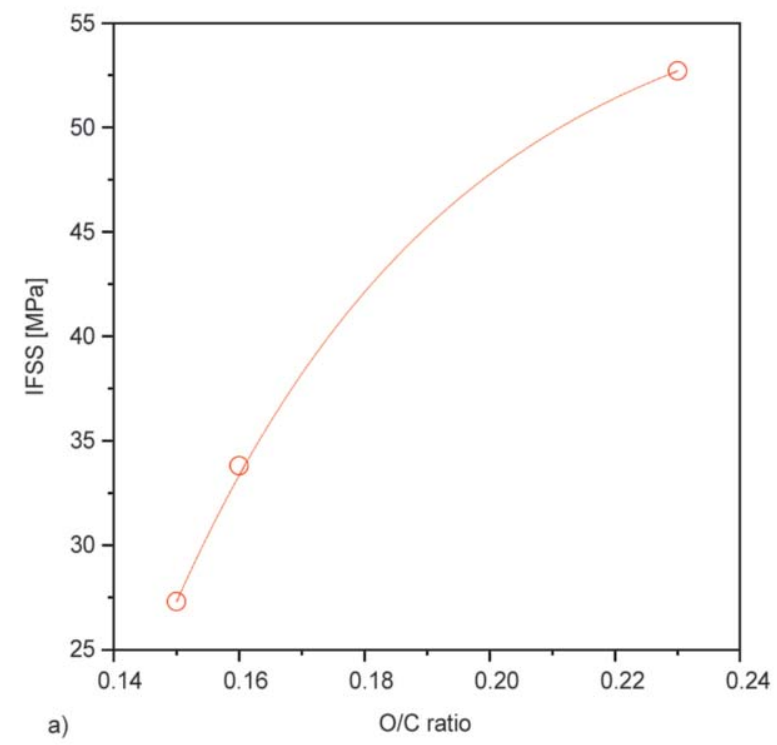

can both effectively increase adhesion that is well illustrated in Figure 12 displaying the measured values of the present test results. The higher polarity of the surface promotes stronger chemical bonding, while the increased roughness enables better mechanical interlocking between the different components of the composite [50]. While Fukunaga and Ueda [6] claimed that the chemical effect of the polar moieties at the CF surface outweighs the role of mechanical interlocking, Kusano et al. concluded [5] that the improved adhesion can be attributed to the increased roughness. A similar conclusion was reached by Altay et al. [47], however, their findings are debatable as the mechanical properties of the investigated $\mathrm{PP} / \mathrm{CF}$ composites do not correlate well with the increased roughness. Zhuonda [51] found that the core mechanism behind the increase in IFSS depends on the applied plasma gas. In argon plasma, the higher roughness, while in oxygen plasma, the higher number of polar groups at the surface of CFs is related to the increased interfacial bond strength. Our results show that both kinds of plasma treatment significantly improved the adhesion; however, DBD plasma was much more effective as compared to RF plasma. A twofold increase in the shear strength was reached after 10 s treatment, while only $23 \%$ rise was recorded for 2 min RF plasma treatment. Considering that $R F$ treatment induced significant changes only in the polarity of the surface, while the roughness remained almost unaffected, we can conclude that chemical changes have a definite effect on the adhesion improvement. Better adhesion of the DBD treated CFs

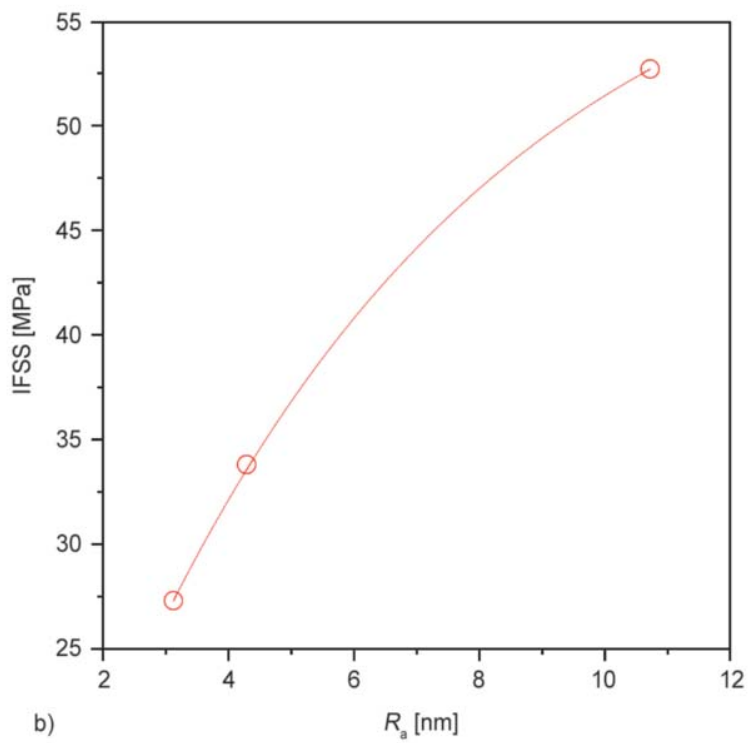

Figure 12. IFSS values with respect to the $\mathrm{O} / \mathrm{C}$ ratio (a) and roughness parameter $\left(R_{\mathrm{a}}\right)(\mathrm{b})$ of the surface of the carbon fiber. 
can be ascribed to either the greater changes in the surface polarity or the increased roughness. Anyway, the two phenomena cannot be separated for DBD treatment. In parallel, however, there could be other parameters that affect adhesion strength. For instance, applying DBD treatment at a lower power of $120 \mathrm{~W}$ Zhang and $\mathrm{Li}$ [52] could attain only a restricted, $c a$. $16 \%$, increase (30 to $35 \mathrm{MPa}$ ) in the IFSS that is similar to our IFSS result using RF plasma.

\section{Conclusions}

We compared the effect of low-pressure RF plasma and atmospheric pressure DBD plasma treatment on the various surface properties of CFs. While both types of plasmas increased the ratio of the polar moieties at the surface, DBD was much more effective as compared to RF plasma. Even a short, $10 \mathrm{~s}$ treatment with DBD plasma resulted in a 33 and $45 \%$ increase in the total $\mathrm{O}$ and $\mathrm{N}$ atomic content, respectively, in the outermost layer. In contrast, RF plasma increased the $\mathrm{O}$ atomic content by only $c a$. $6 \%$, while the $\mathrm{N}$ atomic content by as much as $70 \%$ after a 5 min treatment. The different types of plasma treatment induced different changes in the surface roughness, as well. Whilst the RF plasma did not affect the roughness, DBD treatment resulted in an approximately twofold increase due to its etching effect. Another consequence of the etching is the formation of various flaws at the surface that eventually deteriorated the tensile strength of the plasma-treated CFs. The expected outcome of plasma treatment is the significant improvement of adhesion that increased approximately by 20 and $50 \%$ for RF and DBD plasma treatments, respectively. The comparison of low pressure and atmospheric pressure plasma treatments shows that atmospheric DBD plasma treatment is a more convenient method as compared to RF plasma to achieve increased adhesion between CFs and polymer matrix and prepare $\mathrm{CF}$ reinforced polymer composites.

\section{Acknowledgements}

The authors are grateful to Gábor Babos, the mechanic, for his help in the maintenance and repairing of the DBD plasma unit.

\section{References}

[1] Sharma M., Gao S., Mäder E., Sharma H., Wei L. Y., Bijwe J.: Carbon fiber surfaces and composite interphases. Composites Science and Technology, 102, 3550 (2014).

https://doi.org/10.1016/j.compscitech.2014.07.005
[2] Park S. J.: Carbon fibers. Springer, Dordrecht (2018).

[3] Wang C., Chen L., Li J., Sun S., Ma L., Wu G., Zhao F., Jiang B., Huang Y.: Enhancing the interfacial strength of carbon fiber reinforced epoxy composites by green grafting of poly(oxypropylene) diamines. Composites Part A: Applied Science and Manufacturing, 99, 58-64 (2017).

https://doi.org/10.1016/j.compositesa.2017.04.003

[4] Aussawasathien D., Hrimchum K.: Carboxylic-plasmatreated nanofiller hybrids in carbon fiber reinforced epoxy composites: Dispersion and synergetic effects. Express Polymer Letters, 15, 262-273 (2021).

https://doi.org/10.3144/expresspolymlett.2021.23

[5] Kusano Y., Andersen T. L., Toftegaard H. L., Leipold F., Bardenshtein A., Krebs N.: Plasma treatment of carbon fibres and glass-fibre-reinforced polyesters at atmospheric pressure for adhesion improvement. International Journal of Materials Engineering Innovation, 5, 122/1122/16 (2014).

https://doi.org/10.1504/IJMATEI.2014.060319

[6] Fukunaga A., Ueda S.: Anodic surface oxidation for pitch-based carbon fibers and the interfacial bond strengths in epoxy matrices. Composites Science and Technology, 60, 249-254 (2000).

https://doi.org/10.1016/S0266-3538(99)00118-9

[7] Wicks S. S., de Villoria R. G., Wardle B. L.: Interlaminar and intralaminar reinforcement of composite laminates with aligned carbon nanotubes. Composites Science and Technology, 70, 20-28 (2010).

https://doi.org/10.1016/j.compscitech.2009.09.001

[8] de Volder M. F. L., Tawfick S. H., Baughman R. H., Hart A. J.: Carbon nanotubes: Present and future commercial applications. Science, 339, 535-539 (2013).

https://doi.org/10.1126/science.1222453

[9] Gohardani O., Elola M. C., Elizetxea C.: Potential and prospective implementation of carbon nanotubes on next generation aircraft and space vehicles: A review of current and expected applications in aerospace sciences. Progress in Aerospace Sciences, 70, 42-68 (2014).

https://doi.org/10.1016/j.paerosci.2014.05.002

[10] Ku-Herrera J., Pacheco-Salazar O., Ríos-Soberanis C., Domínguez-Rodríguez G., Avilés F.: Self-sensing of damage progression in unidirectional multiscale hierarchical composites subjected to cyclic tensile loading. Sensors, 16, 400/1-400/13 (2016).

https://doi.org/10.3390/s16030400

[11] Ma P-C., Siddiqui N. A., Marom G., Kim J-K.: Dispersion and functionalization of carbon nanotubes for polymer-based nanocomposites: A review. Composites Part A: Applied Science and Manufacturing, 41, 1345-1367 (2010).

https://doi.org/10.1016/j.compositesa.2010.07.003

[12] Moosburger-Will J., Bauer M., Laukmanis E., Horny R., Wetjen D., Manske T., Schmidt-Stein F., Töpker J., Horn S.: Interaction between carbon fibers and polymer sizing: Influence of fiber surface chemistry and sizing reactivity. Applied Surface Science, 439, 305-312 (2018). https://doi.org/10.1016/j.apsusc.2017.12.251 
[13] Liu F., Shi Z., Dong Y.: Improved wettability and interfacial adhesion in carbon fibre/epoxy composites via an aqueous epoxy sizing agent. Composites Part A: Applied Science and Manufacturing, 112, 337-345 (2018). https://doi.org/10.1016/j.compositesa.2018.06.026

[14] Wu Q., Zhao R., Zhu J., Wang F.: Interfacial improvement of carbon fiber reinforced epoxy composites by tuning the content of curing agent in sizing agent. Applied Surface Science, 504, 144384/1-144384/12 (2020). https://doi.org/10.1016/j.apsusc.2019.144384

[15] Gardner S. D., Singamsetty C. S. K., Wu Z., Pittman C. U.: XPS/ISS investigation of carbon fibers sequentially exposed to nitric acid and sodium hydroxide. Surface and Interface Analysis, 24, 311-320 (1996).

https://doi.org/10.1002/(SICI)10969918(199605)24:5<311::AID-SIA120>3.0.CO;2-Z

[16] Pittman C. U., He G-R., Wu B., Gardner S. D.: Chemical modification of carbon fiber surfaces by nitric acid oxidation followed by reaction with tetraethylenepentamine. Carbon, 35, 317-331 (1997). https://doi.org/10.1016/S0008-6223(97)89608-X

[17] Zhang G., Sun S., Yang D., Dodelet J-P., Sacher E.: The surface analytical characterization of carbon fibers functionalized by $\mathrm{H}_{2} \mathrm{SO}_{4} / \mathrm{HNO}_{3}$ treatment. Carbon, 46, 196 205 (2008).

https://doi.org/10.1016/j.carbon.2007.11.002

[18] Tong Y., Wang X., Su H., Xu L.: Oxidation kinetics of polyacrylonitrile-based carbon fibers in air and the effect on their tensile properties. Corrosion Science, 53, 2484-2488 (2011).

https://doi.org/10.1016/j.corsci.2011.04.004

[19] Takahashi Y., Fujita H., Sakoda A.: Adsorption of ammonia and water on functionalized edge-rich carbon nanofibers. Adsorption, 19, 143-159 (2013). https://doi.org/10.1007/s10450-012-9435-x

[20] Park S-J., Kim J-S.: Anodic surface treatment on activated carbons for removal of chromium(VI). Journal of Colloid and Interface Science, 239, 380-384 (2001). https://doi.org/10.1006/jcis.2001.7582

[21] Tiwari S., Bijwe J., Panier S.: Gamma radiation treatment of carbon fabric to improve the fiber-matrix adhesion and tribo-performance of composites. Wear, 271, 2184-2192 (2011).

https://doi.org/10.1016/j.wear.2010.11.032

[22] Wan Y. Z., Wang Y. L., Huang Y., Luo H. L., Chen G. C., Yuan C. D.: Effect of surface treatment of carbon fibers with gamma-ray radiation on mechanical performance of their composites. Journal of Materials Science, 40, 3355-3359 (2005).

https://doi.org/10.1007/s10853-005-2844-4

[23] Luo H., Xiong G., Ren K., Raman S. R., Liu Z., Li Q., Ma C., Li D., Wan Y.: Air DBD plasma treatment on three-dimensional braided carbon fiber-reinforced PEEK composites for enhancement of in vitro bioactivity. Surface and Coatings Technology, 242, 1-7 (2014). https://doi.org/10.1016/j.surfcoat.2013.12.069
[24] Li H., Liang H., He F., Huang Y., Wan Y.: Air dielectric barrier discharges plasma surface treatment of three-dimensional braided carbon fiber reinforced epoxy composites. Surface and Coatings Technology, 203, 1317 1321 (2009).

https://doi.org/10.1016/j.surfcoat.2008.10.042

[25] Zhang H., Wei L.: Preparation, performance and analysis of carbon fibers with dielectric barrier discharges plasma surface treatment. Advanced Materials Research, 391-392, 8-12 (2012).

https://doi.org/10.4028/www.scientific.net/AMR.391-392.8

[26] Boehm H. P.: Some aspects of the surface chemistry of carbon blacks and other carbons. Carbon, 32, 759-769 (1994). https://doi.org/10.1016/0008-6223(94)90031-0

[27] Klébert S., Tilajka S., Románszki L., Mohai M., Csiszár E., Károly Z.: Degradation phenomena on atmospheric air plasma treatment of polyester fabrics. Surfaces and Interfaces, 22, 100826/1-100826/10 (2021).

https://doi.org/10.1016/j.surfin.2020.100826

[28] Klébert S., Károly Z., Késmárki A., Domján A., Mohai M., Keresztes Z., Kutasi K.: Solvent- and catalysts-free immobilization of tannic acid and polyvinylpyrrolidone onto PMMA surface by DBD plasma. Plasma Processes and Polymers, 14, 1600202/1-1600202/9 (2017).

https://doi.org/10.1002/ppap.201600202

[29] Bismarck A., Kumru M. E., Springer J.: Influence of oxygen plasma treatment of PAN-based carbon fibers on their electrokinetic and wetting properties. Journal of Colloid and Interface Science, 210, 60-72 (1999). https://doi.org/10.1006/jcis.1998.5912

[30] Mujin S., Baorong H., Wu Y., Ying T., Weiqiu H., Youxian D.: The surface of carbon fibres continuously treated by cold plasma. Composites Science and Technology, 34, 353-364 (1989).

https://doi.org/10.1016/0266-3538(89)90004-3

[31] Károly Z., Kalácska G., Zsidai L., Mohai M., Klébert S.: Improvement of adhesion properties of polyamide 6 and polyoxymethylene-copolymer by atmospheric cold plasma treatment. Polymers, 10, 1380/1-380/11 (2018). https://doi.org/10.3390/polym10121380

[32] Stepanova V., Kelar J., Galmiz O., Zemanek M., Slavicek P., Bucek A., Cernak M.: Areal homogeneity verification of plasma generated by diffuse coplanar surface barrier discharge in ambient air at atmospheric pressure. Contributions to Plasma Physics, 57, 182-189 (2017). https://doi.org/10.1002/ctpp.201600093

[33] Mohai M.: XPS MultiQuant: Multimodel XPS quantification software. Surface and Interface Analysis, 36, 828-832 (2004). https://doi.org/10.1002/sia.1775

[34] Evans S., Pritchard R. G., Thomas J. M.: Relative differential subshell photoionisation cross-sections $(\mathrm{MgK} \alpha)$ from lithium to uranium. Journal of Electron Spectroscopy and Related Phenomena, 14, 341-358 (1978). https://doi.org/10.1016/0368-2048(78)80008-5 
[35] Reilman R. F., Msezane A., Manson S. T.: Relative intensities in photoelectron spectroscopy of atoms and molecules. Journal of Electron Spectroscopy and Related Phenomena, 8, 389-394 (1976).

https://doi.org/10.1016/0368-2048(76)80025-4

[36] Gadelmawla E. S., Koura M. M., Maksoud T. M. A., Elewa I. M., Soliman H. H.: Roughness parameters. Journal of Materials Processing Technology, 123, 133 145 (2002).

https://doi.org/10.1016/S0924-0136(02)00060-2

[37] Ţălu Ş.: Micro and nanoscale characterization of three dimensional surfaces: Basics and applications. Napoca Star, Cluj-Napoca (2015).

[38] Kelly A., Tyson W. R.: Tensile properties of fibre-reinforced metals: Copper/tungsten and copper/molybdenum. Journal of the Mechanics and Physics of Solids, 13, 329-350 (1965). https://doi.org/10.1016/0022-5096(65)90035-9

[39] Liu J., Zhang C., Guo S., Xu L., Xiao S., Shen Z.: Microwave treatment of pre-oxidized fibers for improving their structure and mechanical properties. Ceramics International, 45, 1379-1384 (2019).

https://doi.org/10.1016/j.ceramint.2018.08.311

[40] Zhao G., Liu J., Xu L., Guo S.: Study on structure evolution and reaction mechanism in microwave pre-oxidation. Journal of Inorganic and Organometallic Polymers and Materials, in press (2021).

https://doi.org/10.1007/s10904-021-01958-7

[41] Liu J., Xiao S., Shen Z., Xu L., Zhang L., Peng J.: Study on the oxidative stabilization of polyacrylonitrile fibers by microwave heating. Polymer Degradation and Stability, 150, 86-91 (2018).

https://doi.org/10.1016/j.polymdegradstab.2018.02.017

[42] Nohara L. B., Filho G. P., Nohara E. L., Kleinke M. U., Rezendee M. C.: Evaluation of carbon fiber surface treated by chemical and cold plasma processes. Materials Research, 8, 281-286 (2005). https://doi.org/10.1590/S1516-14392005000300010

[43] Kostov K. G., Nishime T. M. C., Hein L. R. O., Toth A.: Study of polypropylene surface modification by air dielectric barrier discharge operated at two different frequencies. Surface and Coatings Technology, 234, 6066 (2013).

https://doi.org/10.1016/j.surfcoat.2012.09.041
[44] Románszki L., Klébert S., Héberger K.: Estimating nanoscale surface roughness of polyethylene terephthalate fibers. ACS Omega, 5, 3670-3677 (2020).

https://doi.org/10.1021/acsomega.9b04211

[45] Beamson G., Briggs D.: High resolution XPS of organic polymers, the Scienta ESCA300 database. Wiley, Chichester (1992).

[46] Kim N. I., Kang H. M., Hong Y. T., Yoon T. H.: Plasma etching and plasma polymerization coating of carbon fibers. Part 2. Characterization of plasma polymer coated carbon fibers. Journal of Adhesion Science and Technology, 16, 1825-1838 (2002).

https://doi.org/10.1163/156856102320396166

[47] Altay L., Bozaci E., Atagur M., Sever K., Tantug G. S., Sarikanat M., Seki Y.: The effect of atmospheric plasma treatment of recycled carbon fiber at different plasma powers on recycled carbon fiber and its polypropylene composites. Journal of Applied Polymer Science, 136, 47131/1-47131/7 (2019). https://doi.org/10.1002/app.47131

[48] Silva L. L. G., Santos A. L., Nascente P. A. P., Kostov K. G.: Atmospheric plasma treatment of carbon fibers for enhancement of their adhesion properties. Journal of Physics: Conference Series, 511, 012082/1-012082/7 (2014).

https://doi.org/10.1088/1742-6596/511/1/012082

[49] Phan L., Yoon S., Moon M-W.: Plasma-based nanostructuring of polymers: A review. Polymers, 9, 417/1417/24 (2017). https://doi.org/10.3390/polym9090417

[50] Della Volpe C., Fambri L., Fenner R., Migliaresi C., Pegoretti A.: Air-plasma treated polyethylene fibres: Effect of time and temperature ageing on fibre surface properties and on fibre-matrix adhesion. Journal of Materials Science, 29, 3919-3925 (1994).

https://doi.org/10.1007/BF00355950

[51] Zhuoda J.: Effects of plasma treatment of carbon fibers on interfacial properties of BMI resin composites. Surface and Interface Analysis, 51, 458-464 (2019). https://doi.org/10.1002/sia.6600

[52] Zhang H., Li W.: Plasma-grafting polymerization on carbon fibers and its effect on their composite properties. Applied Surface Science, 356, 492-498 (2015). https://doi.org/10.1016/j.apsusc.2015.08.016 